\title{
Absence of Evidence Is Not Evidence of Absence - Does Structural Quality Not Matter in Colorectal Cancer Patients' Satisfaction and Quality of Life?
}

\author{
Volker Arndt \\ Division of Clinical Epidemiology and Aging Research, German Cancer Research Center (DKFZ), Heidelberg, Germany
}

Interdisciplinary cancer centres aim to provide well-structured interdisciplinary and evidence-based care of cancer patients. Certification of cancer centres, which has been introduced in Germany in 2003 by the German Cancer Society in order to improve diagnosis, treatment and follow-up care of cancer patients, is based on structural and process related criteria, such as numbers of operations and complications, training, adherence to evidence-based guidelines, interdisciplinary tumour boards and results of patient surveys and referrers. The process of certification is linked with the expectation that improvements in structural and process related characteristics in the treatment of colorectal cancer also result in better outcomes, such as recurrence free survival and health related quality of life. However, there is only little empirical evidence of a connection between structural organisation of cancer care and quality of life of colorectal cancer patients and improvements in survival rates may come to the fore only after years [1].

In this issue of Onkologie, Weißflog et al. [2] compare quality of life, satisfaction and distress in colorectal cancer patients from certified centres with patients from non-certified hospitals. Although patients from certified centres were more satisfied with their medical care than patients treated in noncertified hospitals, patients from certified centres tended report lower quality of life than their peers leading the authors to the conclusion that 'structural improvements in oncological care are not necessarily reflected in better quality of life of patients treated in certified colorectal cancer centers'.

The authors' finding that patients who are treated in a certified cancer centre report high levels of satisfaction with medical care is in line with a recent report of Pfaff et al. [3] studying the experience of breast cancer patients in Germany. In contrast, their results, showing no clear benefit in quality of life among colorectal cancer patients treated in certified cancer centres as compared to patients from non-certified centres, may represent a sobering disappointment at first sight. However, a closer look on the methodological shortcomings puts their results into perspective.

In the study by Weißflog et al. [2], patients from certified cancer centres had a much shorter follow-up (mean: 78 days since last treatment) as compared to patients from non-certified hospitals (mean: 165 days). This difference is critical as quality of life is very fragile during the first year after diagnosis and usually does not follow a linear relation [4, 5]. Also, differences in participation rates have been reported by the authors ( 45 vs. $52 \%$ ), which may result in selection bias. Likewise, differences in tumour stage are evident. Although the differences are not statistically significant and tumour stage has been considered as a confounder, dichotomization of stage might not be sufficient to rule out residual confounding within each category. In addition, differences in quality of staging between certified and non-certified centres may introduce additional bias. Similarly, there are differences in the two groups regarding the proportion of rectal cancer patients. Given the different treatment strategies between colon and rectal cancer patients, failure to adjust for the different proportions of these cancers may also explain some differences with respect to quality of life. In addition, while adjuvant treatment is highly recommended for stage II and stage III rectal cancer and stage III colon cancer patients, recommendations for stage II colon cancer are inconclusive, resulting in huge variation with respect to the application in stage II colon cancer [6]. Without taking into account information regarding therapy, interpretation of the observed differences is very limited. Further difficulties arise from the fact that the authors considered depression and anxiety as confounding factors and not as intermediate factors on the causal pathway because such a model will yield biased results with respect to the association between cancer care and quality of life.

To understand differences in the outcome of cancer patients from certified cancer centres as compared to patients from other hospitals, more information regarding the struc-

\section{KARGER}

Fax +497614520714

Information@Karger.de

www.karger.com (c) 2012 S. Karger GmbH, Freiburg

0378-584X/12/0354-0159\$38.00/0

Accessible online at:

www.karger.com/onk
Volker Arndt, M.D., M.P.H

German Cancer Research Center (DKFZ),

Division of Clinical Epidemiology and Aging Research (C070),

POB 101949, 69009 Heidelberg, Germany

Tel. +49 6221 42-1301, Fax -1302

v.arndt@dkfz-heidelberg.de 
ture and work-up process within the two types of institution would be necessary. Where is the difference in the structure or the work-up process? Likewise potential differences with respect to the socioeconomic and clinical background of the two patient groups have to be considered. A fair comparison relies on fair conditions. As patients within each hospital tend to be more similar than patients from all hospitals combined, clustering effects have to be considered in order to avoid false-positive findings.

The study by Weißflog et al. [2] shows that the evidence of improved outcome after certification is not obvious. Certification of cancer centres started with the objective to provide an assurance to the patients that they will be treated according to state of the art by a network of well-trained specialists. This assurance may affect important treatment decisions by the patient and referrer. Evidence from methodologically sound studies is needed to show whether improvements in structural quality and care also result in improved patient's outcome.

\section{Disclosure Statement}

The author declares no conflict of interest.

\section{References}

1 Engel J, Kerr J, Eckel R, Günther B, Heiss M, Heitland W, Siewert JR, Jauch KW, Hölzel D: Influence of hospital volume on local recurrence and survival in a population sample of rectal cancer patients. Eur J Surg Oncol 2005;31:512-520.

2 Weißflog G, Singer S, Meyer A, Wittekind C, Dietrich A, Weimann A, Brähler E, Ernst J: Quality of life of colorectal cancer patients in certified centers versus non-certified hospitals. Onkologie 2012;35: DOI: $10.1159 / 000337362$.
3 Pfaff H, Alich M, Kowalski C: Patientenbefragung 2010. Ergebnisse der von der Deutschen Krebsgesellschaft e. V. veranlassten Befragung in zertifizierten Brustkrebszentren. Forschungsbericht 032011 der Veröffentlichungsreihe des Instituts für Medizinsoziologie, Versorgungsforschung und Rehabilitationswissenschaft (IMVR) der Universität zu Köln, ISSN: 2190-8257, Köln, 2011.

4 King MT, Kenny P, Shiell A, Hall J, Boyages J: Quality of life three months and one year after first treatment for early stage breast cancer: influence of treatment and patient characteristics. Qual Life Res 2000;9:789-800.
5 Tsunoda A, Nakao K, Hiratsuka K, Tsunoda Y, Kusano M: Prospective analysis of quality of life in the first year after colorectal cancer surgery. Acta Oncol 2007;46:77-82.

6 Jansen L, Hoffmeister M, Chang-Claude J, Koch M, Brenner H, Arndt V. Age-specific administration of chemotherapy and long-term quality of life in stage II and III colorectal cancer patients - a population-based prospective cohort. Oncologist 2011;16:1741-1751. 